\title{
Diagnóstico da implantação do plano de saneamento básico na região de Araçatuba
}

Deployment of diagnosis of basic sanitation plan in Araçatuba region

Despliegue de diagnóstico del plan de saneamiento basico en la región Araçatuba

\author{
Stéfani Tainá Belortti \\ Graduanda, UNIP, Brasil. \\ stefani_belortti@hotmail.com
}

Lucas Roberto Terneiro

Graduando, UNIP, Brasil.

lucasterneiro67@hotmail.com

Rafael Marçal

Professor Mestre, UNIP, Brasil.

rafael_g1@hotmail.com 


\section{INTRODUÇÃO}

As políticas públicas que qualificam a qualidade de vida da população são determinadas por meio de aspectos socioeconômicos e culturais, e mantêm uma interface com as políticas de saúde, meio ambiente e desenvolvimento urbano. O saneamento básico, em seu sentido lato, abrange um conjunto de ações que o homem estabelece para manter ou alterar o ambiente, no sentido de controlar doenças, promovendo saúde, conforto e bem-estar.

Diante do exposto, o saneamento básico tem recebido atenção dos órgãos públicos a fim de melhorar a qualidade de vida da população, abrangendo desta maneira a saúde pública e evitando gastos com cuidados intensivos na vida futura. Segundo o IBGE a falta de saneamento básico pode gerar vários tipos de doenças, desde parasitoses, viroses, doenças bacterianas entre outras, sendo as crianças as mais atingidas (PEREIRA et al 2010). Em países em desenvolvimento a falta de saneamento é endêmica, o que gera um grande agravamento na saúde pública.

Segundo a Organização Mundial de Saúde (OMS), saneamento é:

[...] o controle de todos os fatores do meio físico do homem, que exercem ou podem exercer efeitos nocivos sobre o bem estar físico, mental e social. De outra forma, pode-se dizer que saneamento caracteriza o conjunto de ações socioeconômicas que têm por objetivo alcançar Salubridade Ambiental.

O saneamento básico é uma atividade de responsabilidade dos administradores da cidade, e devem resguardar os direitos dos seres humanos.

[...] cabe aos governos a responsabilidade de estabelecer contextos políticos e reguladores que salvaguardem os direitos dos pobres, melhorem as condições ambientais e coordenem interações setoriais, sejam os serviços produzidos por fornecedores públicos ou privados. Cabe também aos governos a responsabilidade de criar contextos legais e reguladores que ampare a participação do setor privado na provisão dos serviços de infraestrutura (Relatório sobre o Desenvolvimento Mundial-1994).

Diante desta preocupação, o governo estabelece diretrizes nacionais para o saneamento básico através do decreto 7217/2010 o qual ganha relevância em um contexto de profunda desigualdade no acesso a recursos e serviços do meio ambiente urbano. 0 mesmo decreto Regulamenta a Lei no 11.445, de 5 de janeiro de 2007 que estabelece diretrizes nacionais para o saneamento básico.

Na busca pela igualdade social na área do saneamento, o decreto $7217 / 2010$, que regulamenta a Lei 11.445/ 2007, dispõe: 
Art. 3 baseia-se nos seguintes princípios:

I - universalização do acesso;

II - integralidade, compreendida como o conjunto de todas as atividades e componentes de cada um dos diversos serviços de saneamento básico, propiciando à população o acesso na conformidade de suas necessidades e maximizando a eficácia das ações e resultados;

III - abastecimento de água, esgotamento sanitário, limpeza urbana, manejo dos resíduos sólidos e manejo de águas pluviais realizados de formas adequadas à saúde pública e à proteção do meio ambiente;

IV - disponibilidade, em todas as áreas urbanas, de serviços públicos de manejo das águas pluviais adequados à saúde pública e à segurança da vida e do patrimônio público e privado;

$\mathrm{V}$ - adoção de métodos, técnicas e processos que considerem as peculiaridades locais e regionais, não causem risco à saúde pública e promovam o uso racional da energia, conservação e racionalização do uso da água e dos demais recursos naturais; $\mathrm{VI}$ - articulação com as políticas de desenvolvimento urbano e regional, de habitação, de combate à pobreza e de sua erradicação, de proteção ambiental, de recursos hídricos, de promoção da saúde e outras de relevante interesse social voltadas para a melhoria da qualidade de vida, para as quais o saneamento básico seja fator determinante;

VII - eficiência e sustentabilidade econômica;

VIII - utilização de tecnologias apropriadas, considerando a capacidade de pagamento dos usuários e a adoção de soluções graduais e progressivas;

IX - transparência das ações, baseada em sistemas de informações e processos decisórios institucionalizados;

$\mathrm{X}$ - controle social;

$\mathrm{XI}$ - segurança, qualidade e regularidade; e

XII - integração das infraestruturas e serviços com a gestão eficiente dos recursos hídricos.

Sendo assim, o saneamento urbano pode ser definido como o conjunto de obras que promovam o saneamento no meio urbano e que compreende quatro grandes eixos: abastecimento de água; coleta tratamento e disposição dos esgotos sanitários; drenagem e águas pluviais; e coleta, tratamento e disposição final de resíduos sólidos.

As políticas públicas de saneamento urbano têm grande importância em urbanizações que cresceram em um contexto acelerado, muitas vezes marginalizando as atenções necessárias ao bom desenvolvimento do saneamento, gerando assim problemas que agora interferem na qualidade de vida da população.

\section{OBJETIVO}

O objetivo desta pesquisa é desenvolver um diagnóstico quantitativo da implantação do Plano de Saneamento Básico Municipal na região de Araçatuba, Estado de São Paulo. 


\section{METODOLOGIA}

A metodologia consiste na revisão bibliográfica de livros, artigos, sites especializados para a formulação da base da pesquisa, após houve a coleta de dados nos municípios da região de Araçatuba, Estado de São Paulo, a partir do Plano de Saneamento Básico Municipal. Outro aspecto a ser considerado é se realmente as cidades têm o Plano de Saneamento Básico regulamentado por lei aprovada na câmara municipal.

A partir desse contato com as prefeituras e outros órgãos públicos, os dados coletados servirão de base para a elaboração de gráficos e tabelas das análises. Outro item relevante a ser abordado é a quantidade de habitantes.

Resumidamente, serão classificados três tipos de cidades:

Tipo I: aquelas que possuem o Plano aprovado;

Tipo II: aquelas que não possuem o Plano aprovado;

Tipo III: aquelas que o Plano está em elaboração.

\section{JUSTIFICATIVA}

A água é um dos principais elementos para a sobrevivência dos seres humanos e dos animais, porém nem todos têm acesso digno a uma água potável. Um estudo feito pelo BNDES avalia que a deficiência e a escassez da água limpa, a escassez de um sistema de coleta, tratamento e disposição do esgoto sanitário e da falta do Plano de Saneamento Básico sejam os responsáveis por $65 \%$ das internações de crianças em hospitais.

Para cada dólar investido em água e saneamento, são economizados 4,3 dólares em custos de saúde no mundo; 2,5 bilhões de pessoas ainda sofrem com a falta de acesso a serviços de saneamento básico e 1 bilhão pratica a defecação ao ar livre (WHO, 2014).

A falta de saneamento urbano pode ocasionar uma série de problemas ambientais visíveis e invisíveis, como colocar em risco a saúde da população local, contaminação dos rios e outros fatores que agridem o meio ambiente. Em razão disso, foi elaborada uma lei para criar um Plano de Saneamento Básico Municipal, a Lei no 11.445/2007, na qual estabelece diretrizes nacionais para o saneamento básico.

O estudo da implantação do Plano de Saneamento Básico Municipal permite verificar como está sendo feito, dentre outros fatores, a gestão do sistema de tratamento de água, coleta tratamento e disposição final de esgoto sanitário dos municípios envolvidos e, simultaneamente, a preservação das questões ambientais, sociais e sustentáveis para garantir um e futuro melhor às gerações. 


\section{RESULTADOS}

A pesquisa envolve os 43 municípios presentes na região de Araçatuba, a fim de obter o maior número de resultados possíveis para aprimorar cada vez mais o ojetivo da pesquisa.

Dos 43 municípios analisados, apenas 17 cidades atendem a Lei Federal de Saneamento Básico (lei 11.445/07) contendo o plano aprovado pela câmara municipal de seus respectivos municípios, 12 estão com o Plano de Saneamento Básico em elaboração, 12 não possuem o Plano e 2 cidades não responderam (gráfico 1.1).

Sendo assim, as cidades são classificadas em três categorias:

Tipo I: aquelas que possuem o Plano aprovado: Alto Alegre, Andradina, Araçatuba, Barbosa, Bento de Abreu, Buritama, Castilho, Coroados, Glicério, Guaraçai, Itapura, Lavínia, Muritinga do Sul, Piacatu, Rubiácea, Sud de Mennuci e Valparaíso.

Tipo II: aquelas que não possuem o Plano aprovado: Auriflama, Avanhandava, Bilac, Gabriel Monteiro, Gastão Vidigal, General Salgado, Guararapes, Lourdes, Nova Independência, Nova Luzitânia, Penápolis e Santópolis do Aguapeí.

Tipo III: aquelas que estão com o Plano em elaboração: Birigui, Braúna, Brejo Alegre, Guzolândia, Ilha Solteira, Luiziânia, Mirandópolis, Nova Castilho, Pereira Barreto, Santo Antônio do Aracanguá, Suzanápolis e Turiúba.

Gráfico 1.1: Representação dos municípios que possuem ou não o Plano de Saneamento Básico na região de Araçatuba.

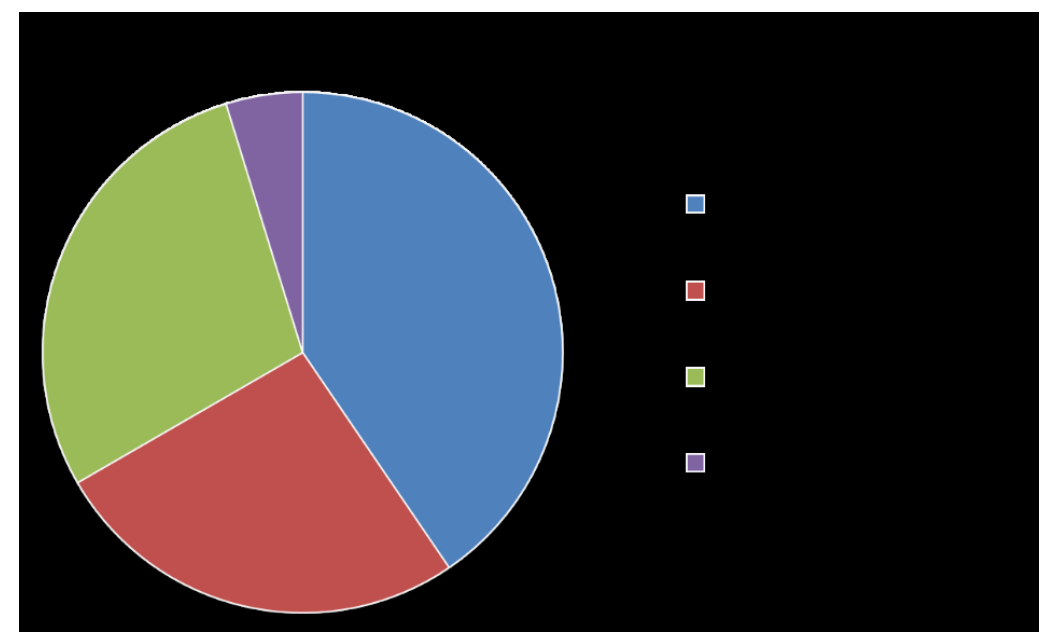

Fonte: BELORTTI, 2016.

Após entrar em contato com as cidades e verificar quantos possuem ou não o Plano, foi realizado uma análise em relação a população do município pelo Plano. Do total dos municípios que possuem o plano, apenas 12 têm a população entre 0001 a 10.000 habitantes; 


\section{CONCLUSÃO}

O Levantamento da pesquisa mostra quais os municípios possuem o Plano e se de fato eles estão sendo colocados em prática, conforme está presente na lei do município após a aprovação na câmara. Os municípios que ainda não possuem o Plano ou que ainda não colocaram em prática suas diretrizes, demonstram os malefícios que estão trazendo ao meio ambiente com o descarte de esgoto sem o tratamento adequado.

É possível relatar, em uma análise geral, que poucos municípios possuem o Plano de Saneamento Básico, na qual é de suma importância para a saúde e o bem-estar de todos. A presença desse Plano nos municípios demonstra a preocupação deles com o meio ambiente e com a saúde da população.

A pesquisa, tornando-se pública, irá alertar a sociedade e os órgãos públicos dos riscos que eles estarão sofrendo sem o tratamento adequado da água e quando agridem a questão ambiental de forma irracional ou até mesmo racional pelo despejo de esgoto in natura. Assuntos sobre o meio ambiente não devem ficar apenas no papel, mas serem colocados em práticas de forma rigorosa.

\section{AGRADECIMENTO}

Agradecemos, primeiramente, a Deus pela força e energia para realizar essa pesquisa, ao nosso orientador e professor Rafael Marçal por nos orientar e transmitir o seu conhecimento, a coordenadora e professora Gislaine Bianchi por nos incentivar e aos familiares por acreditar em nós.

\section{REFERÊNCIAS BIBLIOGRÁFICAS}

BANCO MUNDIAL- Relatório sobre o Desenvolvimento Mundial-1994 - Infraestrutura para o Desenvolvimento. Rio de Janeiro, Fundação Getúlio Vargas, 1994.

CARDOSO, F.D.P. et.al. Prevalência de enteroparasitoses em escolares de 06 a 14 anos no município de Araguaína Tocantins. Revista Eletrônica de Farmácia. 2010, v.7, n.1, pp.54-64.

Estação de tratamento de esgoto. Legislação - Lei 11.445/07. Disponível em: < http://www.meioambiente.ufrn.br/ete/?p=65 > Acesso em: 29 de março de 2016.

MORETTI, J.S; MORETTI, R.S. Saneamento Como Importante Elemento do Direito à Cidade: Ponderações Sobre a Política Municipal de Saneamento em São Paulo. Revista eletrônica: Direito, Estado e Sociedade. Jul / dez 2014, n. 45 pag. 61 a 81.

Trata Brasil. O que é Saneamento? Disponível em: < http://www.tratabrasil.org.br/o-que-e-saneamento > Acesso em: 28 de março de 2016. 
Revista Nacional de

Gerenciamento de Cidades

National Journal of Cities Management

UOL Cotidiano. Censo 2010. Disponível em : < http://noticias.uol.com.br/cotidiano/ultimasnoticias/2012/11/13/estudo-do-ibge-mostra-que-mais-de-70-dos-municipios-nao-tem-politica-de-saneamentobasico.htm > Acesso em: 28 de março de 2016.

World Health Organization. Investing in water and sanitation: increasing access reducing inequalities. Disponível em < http://www.who.int/water_sanitation_health/publications/glaas_report_2014/en/> Acesso: 28 de março de 2016. 